University of Nebraska - Lincoln

DigitalCommons@University of Nebraska - Lincoln

Faculty Publications - Textiles, Merchandising and Fashion Design

Textiles, Merchandising and Fashion Design,

Department of

2007

\title{
Structure and Properties of Chicken Feather Barbs as Natural Protein Fibers
}

Narendra Reddy

University of Nebraska - Lincoln, nreddy3@unl.edu

Yiqi Yang

University of Nebraska-Lincoln, yyang2@unl.edu

Follow this and additional works at: https://digitalcommons.unl.edu/textiles_facpub

Part of the Art and Design Commons

Reddy, Narendra and Yang, Yiqi, "Structure and Properties of Chicken Feather Barbs as Natural Protein Fibers" (2007). Faculty Publications - Textiles, Merchandising and Fashion Design. 26.

https://digitalcommons.unl.edu/textiles_facpub/26

This Article is brought to you for free and open access by the Textiles, Merchandising and Fashion Design, Department of at DigitalCommons@University of Nebraska - Lincoln. It has been accepted for inclusion in Faculty Publications - Textiles, Merchandising and Fashion Design by an authorized administrator of DigitalCommons@University of Nebraska - Lincoln. 
Published in Journal of Polymers and the Environment 15 (2007), pp. 81-87; doi: 10.1007/s10924-007-0054-7

Copyright (C) 2007 Springer Science+Business Media, LLC. Used by permission.

Published online March 28, 2007

\title{
Structure and Properties of Chicken Feather Barbs as Natural Protein Fibers
}

\author{
Narendra Reddy ${ }^{1}$ and Yiqi Yang ${ }^{1,2}$
}

1. Department of Textiles, Clothing and Design, University of Nebraska-Lincoln, 234, HE Building, Lincoln, NE 68583-0802, USA

2. Department of Biological Systems Engineering, University of Nebraska-Lincoln, 234, HE Building, Lincoln, NE 68583-0802,

USA

Corresponding author - Y. Yang, email yyang2@unl.edu

\begin{abstract}
The structure and properties of chicken feather barbs makes them unique fibers preferable for several applications. The presence of hollow honeycomb structures, their low density, high flexibility and possible structural interaction with other fibers when made into products such as textiles provides them unique properties unlike any other natural or synthetic fibers. No literature is available on the physical structure and tensile properties of chicken feather barbs. In this study, we report the physical and morphological structure and the properties of chicken feather barbs for potential use as natural protein fibers. The morphological structure of chicken feather barbs is similar to that of the rachis but the physical structure of the protein crystals in chicken feather barbs is different than that reported for feather rachis keratin. The tensile properties of barbs in terms of their strength and modulus are similar but the elongation is lower than that of wool. Using the cheap and abundant feathers as protein fibers will conserve the energy, benefit the environment and also make the fiber industry more sustainable.
\end{abstract}

Keywords: feathers, barbs, protein fibers, structure, properties

\section{Introduction}

Chicken feathers have unique structure and properties not found in any natural or synthetic fibers. Although feathers as such cannot be processed as the protein fibers wool and silk due to the complex structure of the feathers, the secondary structures of feathers i.e. the barbs have the structure and properties that make them suitable for use as natural protein fibers. The low density, excellent compressibility and resiliency, ability to dampen sound, warmth retention and distinctive morphological structure of feather barbs make them unique fibers. For example, the density chicken feathers is about $0.8 \mathrm{~g} / \mathrm{cm}^{3}$ compared to about $1.5 \mathrm{~g} / \mathrm{cm}^{3}$ for cellulose fibers and about $1.3 \mathrm{~g} / \mathrm{cm}^{3}$ for wool [1, 2]. None of the natural or synthetic fibers commercially available today have a density as low as that of chicken feathers. Such unique properties make barbs preferable for many applications such as textiles and composites used for automotive applications. In addition to the unique structure and properties, barbs are cheap, abundantly available and a renewable source for protein fibers.

Finding alternative sources to replace at least a part of the 67 million tons of natural and synthetic fibers currently in use is important due to the decreasing availability of resources required to produce the natural and synthetic fibers [3]. The decreasing availability of natural resources will restrict the availability and/or increase the price of both the natural and synthetic fibers currently in use. Therefore, attempts are being made to use annually renewable lignocellulosic agricultural byproducts such as cornhusks, cornstalks and pineapple leaves as an alternative source for cellulosic fibers [4-9]. Similarly, attempts have also been made to use agricultural byproducts containing proteins such as zein in corn and 
soyaproteins as a source to produce regenerated protein fibers [10-12]. However, none of the attempts on producing high quality protein fibers from agricultural byproducts have been commercially successful.

Poultry feathers contain about $90 \%$ protein and are a cheap and renewable source for protein fibers [1]. The secondary structures of the feathers, the barbs are in fibrous form and could be a potential source as protein fibers. More than 4 billion pounds of chicken feathers are produced in the world every year [13]. About 50\% of the weight of the feathers is barbs and the other $50 \%$ is rachis [1]. Even assuming that $20 \%$ of the barbs have lengths greater than 1 inch required for textile applications, about 400 million pounds of barbs will be available as natural protein fibers every year. This means an availability of $8 \%$ of the protein fibers consumed in the world every year. Since the two natural protein fibers wool and silk are relatively expensive fibers, using the low cost barbs as protein fibers will make many protein fiber products to be economical and also add high value to the feathers.

Current applications of chicken feathers are mainly in composites and non-woven fabrics $[1,14]$. Recently, several attempts on using the barbs as "feather fibers" for composites and non-wovens have been reported [1, 14]. These feather fibers have been recently characterized for their micro structural properties [15]. However, commercially available feather fibers are the barbs in a pulverized form with lengths of about 0.3$1.3 \mathrm{~cm}$ [1]. Feather fibers do not have the lengths required to be processable on textile machines and are therefore not suitable for making spun yarns and woven fabrics in $100 \%$ form or as blends with other natural and synthetic fibers. Being able to produce yarns and fabrics from barbs is important because of the potential for higher value addition and the large textile market.

Although several researchers have reported the structure and properties of feathers from various birds, most of the work has been done on the feather in its entirety and mostly on the feather rachis [16-18]. Limited work has been done on elucidating the structure and properties of feather barbs, especially the chicken feather barbs. The physical and morphological structure, properties and the suitability of chicken feather barbs as protein fibers for high value textile applications has not been studied. On the other hand, turkey feather barbs have been characterized for their properties and used as textile fibers and processed to produce blended yarns and non-woven fabrics [14]. However, only the tensile properties of turkey feathers have been reported in this paper and the morphology and physical structure of the feathers has not been studied in detail. It would be necessary to understand the structure and proper- ties of chicken feather barbs in order to determine their suitability for various applications. In this research, we have characterized chicken feather barbs for their physical and morphological structure and properties with a view to evaluate their suitability as textile fibers. The structure and properties of chicken feather barbs have been compared with the most common natural protein fiber, wool.

\section{Materials and Methods}

\section{Materials}

Chicken feathers were obtained from a poultry processing facility in India. Feathers were used as received for the structure and property studies. Barbs with the barbules were manually cut from the rachis of the feathers. The feather barbs used for this study had lengths in the range of $3-4.5 \mathrm{~cm}$.

\section{Barb Fineness}

Fineness of textile fibers is defined in terms of denier which is the weight in grams of 9,000 $\mathrm{m}$ of the material. Fineness of barbs was determined by weighing a known length of the barbs.

\section{Morphological Structure}

A Hitachi 3000 N Scanning Electron Microscope was used to study the longitudinal and cross-sectional features of the barbs. Barbs were mounted on a conductive adhesive tape and sputter coated with gold palladium prior to observation in the SEM. A $15 \mathrm{kV}$ voltage was used for all the observations.

\section{$X$-ray Studies}

A Bruker D8 Discover model diffractometer equipped with a General Area Detector Diffraction System (GADDS) and a Rigaku D-max/B $\Theta / 2 \Theta$ X-ray diffractometer with Bragg-Brentano parafocusing geometry, a diffracted beam monochromator, and a copper target X-ray tube set to $40 \mathrm{kV}$ and $30 \mathrm{~mA}$ used for the $X$-ray diffraction studies. Diffraction patterns of the chicken feather rachis, barbs and wool were obtained on the Bruker diffractometer. Samples were mounted on a specially designed sample holder so that the X-ray beam was perpendicular to the sample.

The feather barbs and wool were powdered in a Wiley mill to about $250 \mu \mathrm{m}$ in size and made into pellets. The pellets were used to obtain X-ray diffraction patterns from the Rigaku diffractometer and the diffractograms were analyzed for $\%$ crystallinity and d-spacings. Diffraction patterns were recorded with a $2 \Theta$ range of $2-40^{\circ}$ using a copper target $\mathrm{X}$-ray tube set to $40 \mathrm{kV}$ and 
$30 \mathrm{~mA}$ with a $1 / 2$ inch divergent slit. \% crystallinity of the samples was calculated by manually subtracting the background and amorphous regions from the crystalline peaks.

\section{Tensile Properties}

Barbs were mounted on an Instron tensile testing machine to measure the tensile properties. A gauge length of 1 inch and crosshead speed of $18 \mathrm{~mm} / \mathrm{min}$ was used for testing the feather barbs. Three sets of 20 barbs each were tested for the tensile properties and the average and \pm one standard deviations are reported. The barbs and wool fibers were conditioned for $24 \mathrm{~h}$ before testing under standard conditions of $21 \pm 1{ }^{\circ} \mathrm{C}$ and relative humidity of $65 \pm 5 \%$ according to ASTM standard D1776.

\section{Moisture Regain}

The amount of moisture regained by the barbs under standard textile testing conditions of $65 \%$ relative humidity (RH) and $21^{\circ} \mathrm{C}$ was determined. Barbs were first dried in a hot air oven at $105^{\circ} \mathrm{C}$ for $4 \mathrm{~h}$. The dried samples were allowed to regain moisture under the standard testing conditions of $21^{\circ} \mathrm{C}$ and $65 \% \mathrm{RH}$. The ratio of the dry weight of the barbs to the conditioned weight was taken as the $\%$ moisture regain.

\section{Results and Discussion}

\section{Morphological Structure}

The morphological features of feather barbs are shown in Figures 1-4. A feather is mainly composed of three distinct units as shown in Figure 1. The central shaft of the feather is called the rachis to which are attached the secondary structures, the barbs. The tertiary structures of the feathers, the barbules are attached to the barbs in a manner similar to the barbs being attached to the rachis. A rachis runs the entire length of the feather and could be up to 7 inches in length. The barbs have lengths anywhere from 1 to $4.5 \mathrm{~cm}$ depending on their location along the length of the rachis. Barbs at the base of the rachis are longer than those at the tip. The tertiary structures, the barbules have lengths of about $0.3-0.5 \mathrm{~mm}$ and have hook like structures at their tips as shown in Figure 2.

The feather rachis is thick and stiff and not suitable as a natural protein fiber. On the other hand, feather barbs have the length, strength and flexibility that make them suitable as natural protein fibers. In addition, barbs have a unique cross-section that is not seen in the natural protein fibers wool and silk. Feather barbs have honeycomb shaped hollow cells in the cross-section as seen from

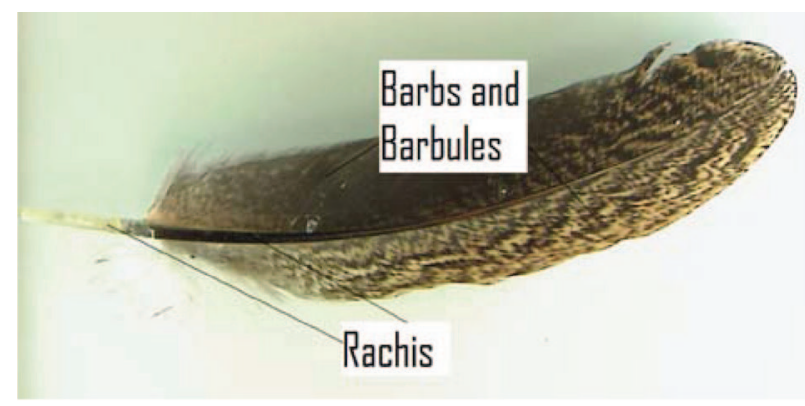

Figure 1. Photograph of a chicken feather showing the three structural levels of the feather. The Rachis is the primary, the barbs are the secondary and the barbules that are attached to the barbs (not seen at this magnification) are the tertiary structures of the feathers

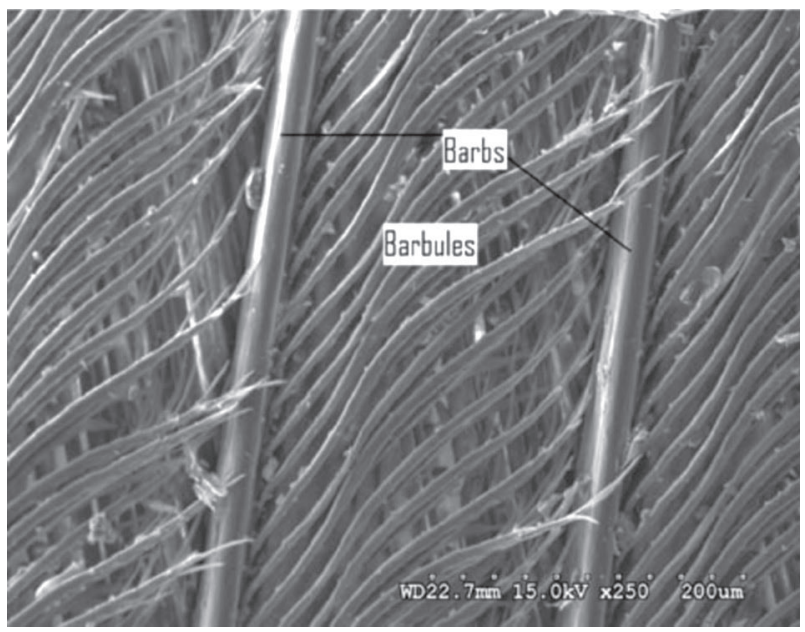

Figure 2. SEM picture showing the tertiary structure of feathers, the barbules that are attached to the barbs. The barbules have lengths of about $0.3-0.5 \mathrm{~mm}$ and have hooks at their ends

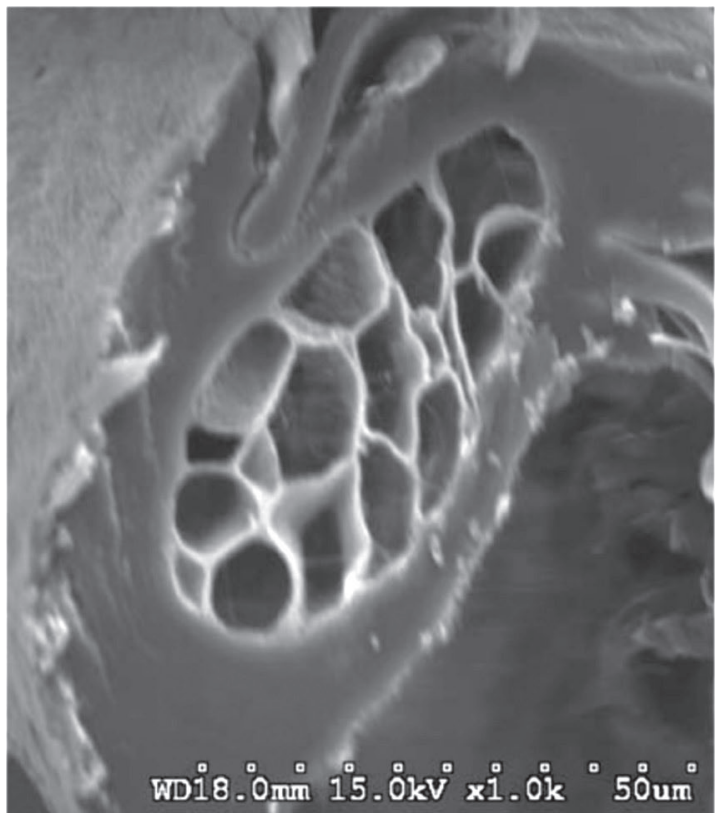

Figure 3. SEM picture of the cross-section of a barb showing the hollow honeycomb shaped structures 


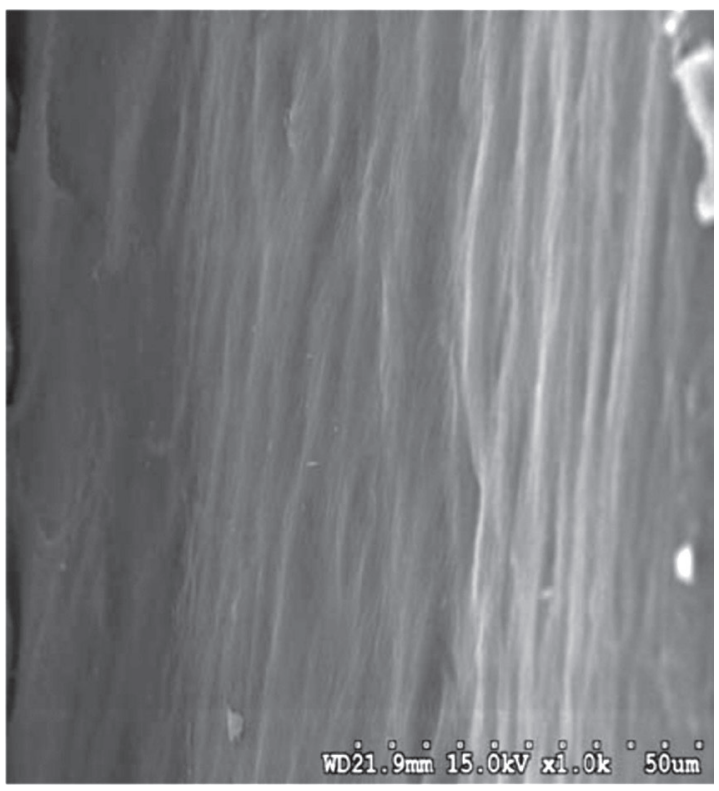

Figure 4. SEM picture of the surface of the barbs shows fibrillar structure but no scales as seen in wool

Figure 3. These hollow cells act as air and heat insulators and are therefore suitable for applications such as composites used for automobiles where materials that can absorb sound are preferred. The honeycomb structure is also said to provide high resistance to compressibility [19]. The presence of hollow honeycomb structures makes barbs to be very light in weight. The light weight of the feathers combined with their heat insulating capability makes feathers preferable for applications such as outer wear jackets. Longitudinally, barbs have a fibrillar surface as seen in Figure 4 but have no scales as seen in wool.

The presence of barbules which are the secondary structures of the barbs can provide a unique structural interaction with other fibers when barbs are used to produce blended yarns. The barbules can also entangle with other fibers and improve the mechanical properties of fibrous composites. Barbs are said to be more flexible than rachis and also twist when they are bent even when groups of barbs are together [20]. The ability of the barbs to twist and bend will provide better cohesiveness, spinnability and durability to yarns and fabrics made from them. Figure 5 shows a hand spun yarn made from a blend of about $70 \%$ cotton and 30\% colored chicken feather barbs. As seen from the figure, the barbs are intertwined and twisted with the cotton fibers. A higher magnification SEM picture of a portion of the yarn is shown in Figure 6. It can be seen from the figure that the cotton fibers are entangled with the barbules of the feathers. The structural interaction of the barbs, the barbules and the hooks in the barbules with other blended fibers provides better entanglement and

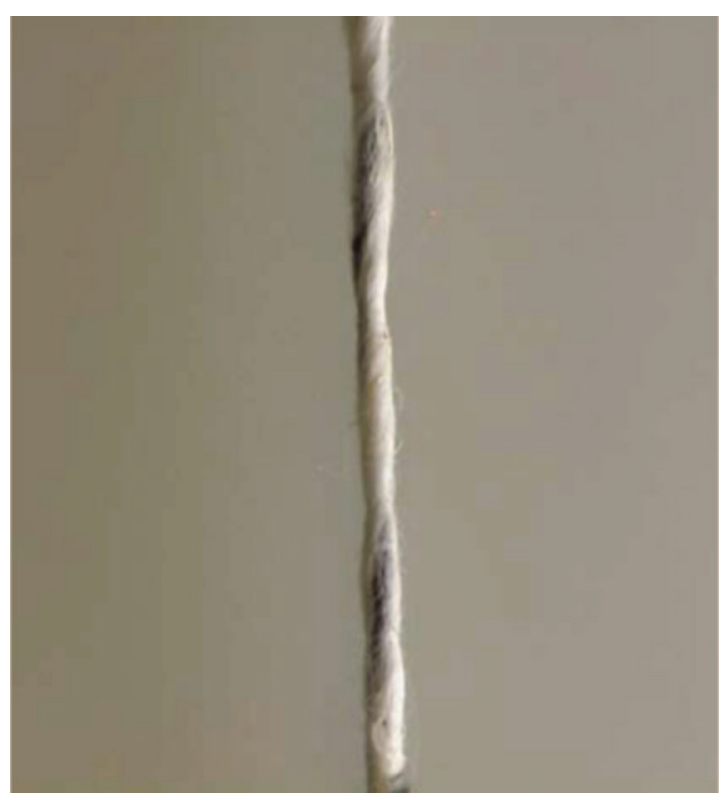

Figure 5. Photograph of a hand spun chicken feather barb/cotton blended yarn. The barbs are intertwined and twisted with the cotton fibers. The barbules in the barbs are expected to provide better cohesiveness and therefore greater strength to the yarns.

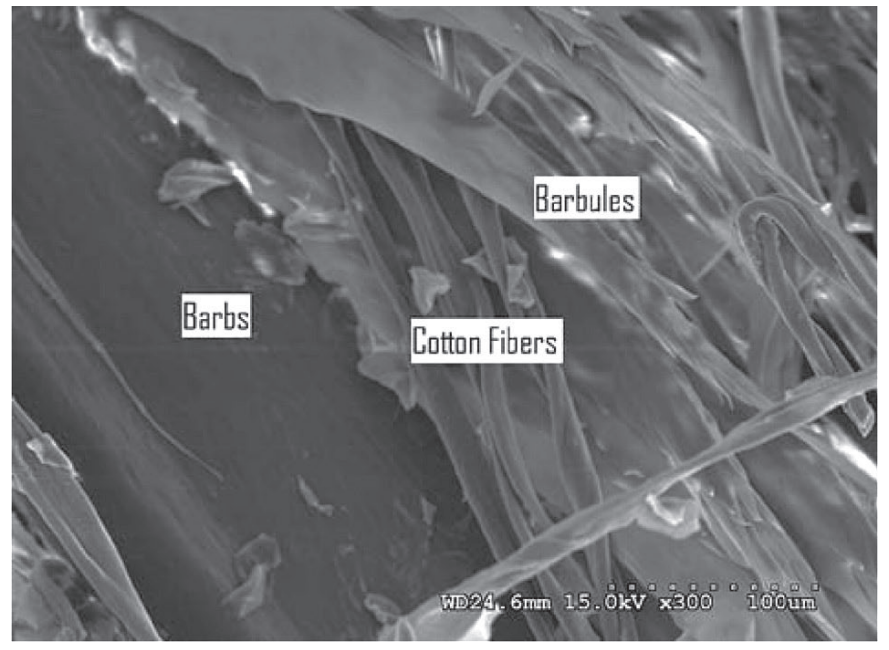

Figure 6. SEM picture of a portion of the barb/cotton hand spun yarn. The barbules are intertwined with the cotton fibers. This structural interaction is expected to provide better cohesiveness and therefore higher strength to the yarns.

therefore cohesiveness to the yarns. Such structural interaction between fibers is not possible with any other natural or synthetic fibers available today. In addition, the flexibility of the barbs and their ability to be twisted when bent are properties that will contribute to the strength of the yarns [20]. The actual effect of the interaction between feather barbs and fibers in a spun yarn and their effect on the properties of the yarns warrants further research. 

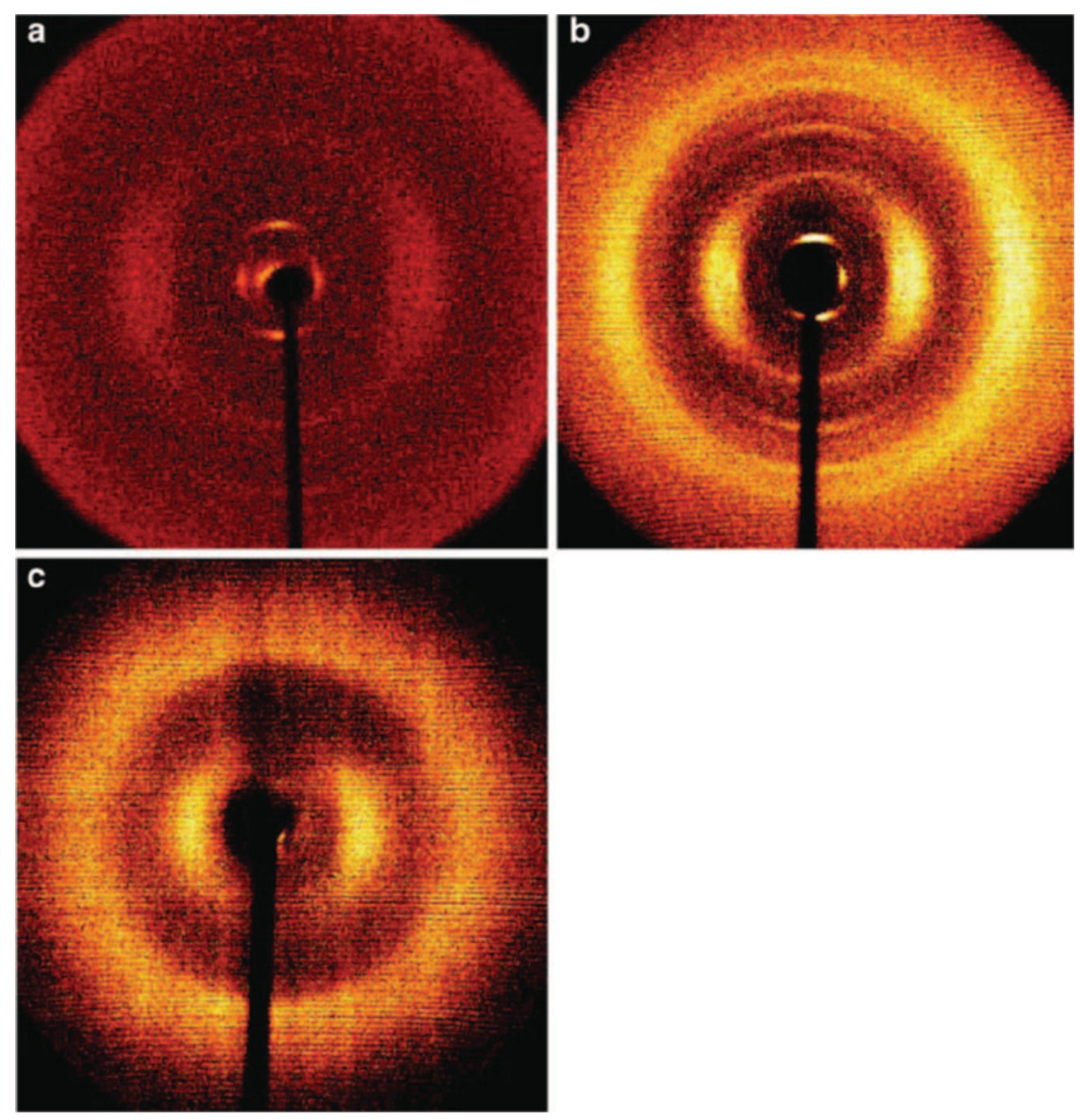

Physical Structure

The physical structure of chicken feathers in terms of the shape and size of protein crystals, the d-spacings of the lattices in the crystals and the \% crystallinity of the feathers has not been clearly elucidated. No recent reports are available on studying the detailed physical structure of feathers and the only literature available is from the classical work in the early $1940 \mathrm{~s}$ by Pauling and Kraut [17, 18, 21-23]. However, these researchers have published contrasting results on the shape of the crystals in feathers and the d-spacings of the crystals. In addition, most of the reported work has been done on the rachis of seagull feathers and not on the rachis or barbs of chicken feathers. More recently, Cameron and others have related the X-ray diffraction patterns of the rachis of three different birds to their Young's modulus. Few reflections in both the meridian and equatorial directions have been reported in this study compared to the earlier work of Pauling and Kraut [16].

A diffraction patterns of a chicken feather rachis, barb and wool are shown in Figure 7a, b and c respectively. As seen from the Figures, the rachis produces a bright, sharp and more number of diffracting peaks than the barbs. However, the barbs have bright and sharp
Figure 7. Diffraction pattern of a chicken feather barbs (a) bright and sharp diffraction patterns at the center but broad and diffuse and weak diffracting spots at the middle of the pattern. The rachis (b) shows more diffracting spots in both the equatorial and meridional directions compared to those seen in the barbs. Diffraction pattern of a wool fiber (c) shows weak and broad diffraction pattern.

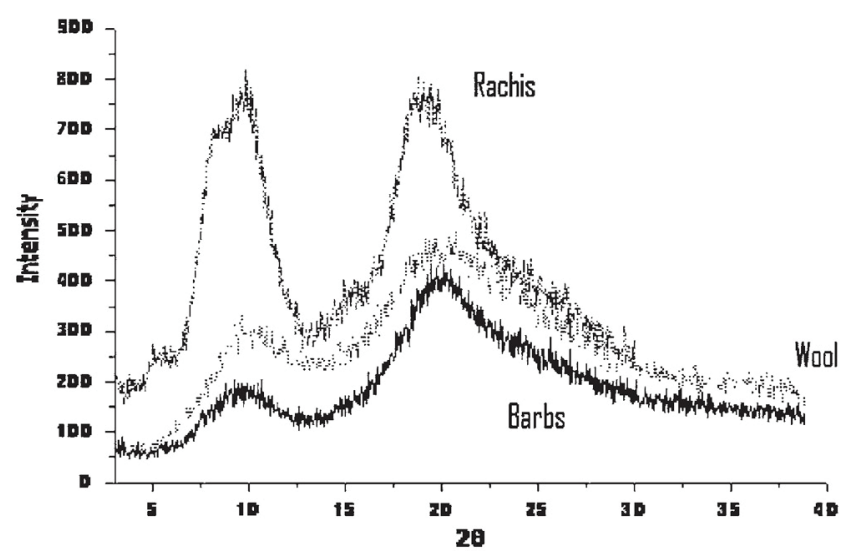

Figure 8. Diffraction intensities of rachis and barbs of chicken feathers with wool

diffraction patterns compared to those seen in wool depicted in Figure 7c. The diffraction patterns of the barbs (7a) indicate that the crystals in barbs are more oriented than the crystals in wool (7c) but less oriented than the crystals in rachis $(7 \mathrm{~b})$ [21].

The diffraction intensities of the rachis, barbs and wool are compared in Figure 8. As seen from the figure, the rachis produces more crystalline peaks than the barbs and wool. The diffraction patterns of wool and barbs are very similar to each other and therefore have similar \% crystallinities. The \% crystallinity of wool and 
Table 1. d-spacing in Angstroms of feather rachis and barbs. The values for the rachis are from literature $[17,18]$.

\begin{tabular}{llll}
\hline Rachis & \multicolumn{3}{l}{ Barbs } \\
\hline Equatorial & Meridional & Equatorial & Meridional \\
33.3 & 23.1 & 35.3 & 23.33 \\
17.1 & 6.2 & 10.63 & 8.99 \\
11.0 & 4.9 & 9.47 & 6.23 \\
8.56 & 4.37 & 8.78 & - \\
4.68 & 3.07 & 4.66 & - \\
\hline
\end{tabular}

- indicates that no reflections corresponding d-spacings were observed

barbs from the diffraction patterns shown in Figure 8 was found to be 25.6 and $24.8 \%$, respectively.

Table 1 shows the $\mathrm{d}$-spacings of feather rachis keratin reported in literature and the d-spacings of the barbs determined in this study. It should be noted that the weak and diffuse scattering of the X-rays by the barbs makes it difficult to clearly identify all the d-spacings of the crystals in barbs. Therefore, the d-spacings reported here is at best an average of several d-spacings obtained from the overlapping peaks. As seen from Table 1 , the barbs have a few equatorial spacings different than those found in the rachis. Both the rachis and barbs show the 33.8 and $4 \AA$ reflections whereas the $9 \AA$ reflections in barbs are not seen in the rachis. More number of meridian reflections are found on the rachis than on the barbs. The 4 and $3 \AA$ reflections on the meridian reported for the rachis were not seen in the barbs. Based on the diffraction patterns and the differences in the dspacings between rachis and the barbs, it is reasonable to assume that the protein crystals in the barbs have a different arrangement than that in the rachis. However, the similarity of the peaks between wool and barbs as shown in Figure 8 and the presence of the $4.5 \AA$ diffracting plane at the $2 \Theta$ position of $19.5^{\circ}$ gives sufficient evidence that the protein in barbs is of the a-keratin form.

Two types of unit structures, the pseudo-orthorhombic triclinic unit and the hexagonal unit have been proposed for feather keratin. Pauling and Corey have reported that feather keratin has a pseudo-orthorhombic triclinic unit with dimensions of $\mathrm{a}_{0}, \mathrm{~b}_{0}$ and $\mathrm{c}_{0}$ of $9.5,34.2$, and $94.6 \AA$, respectively and $\alpha, \beta$, and $\gamma$ angles of $90^{\circ}$ [17]. Extending on Pauling's work, Kraut has estimated the unit structure of feather keratin to be a hexagonal unit with dimensions of $\mathrm{a}_{0}, \mathrm{~b}_{0}$ and $\mathrm{c}_{0}$ of 38.7, 34.2, and $95.4 \AA$, respectively. We were unable to find any literature on validating the keratin structure proposed by Pauling or Kraut. Also, we did not attempt to develop a crystal structure for feather keratin in this study due to the diffuse nature of the peaks from barbs and the difficulty in obtaining unambiguous $\mathrm{d}$-spacings required to predict the crystal structure.

Although the physical structure of barbs in terms of the d-spacings reported here cannot be used to conclusively determine the structure of the crystals in the barbs, there is sufficient evidence indicating that the rachis and barbs have different crystal structures or at least different arrangement of the crystals along their axis. Further research using stronger radiation sources such as synchrotron sources could possibly lead to a better understanding of the structure of protein crystals in various parts of the feathers.

Tensile Properties

The tensile properties of chicken feather barbs are compared with those of wool and turkey feathers in Table 2 and Figure 9. The values for turkey feathers and wool in Table 2 are from literature and for chicken feathers are from this research $[2,14]$. Chicken feathers have barbs with lengths in the range of $1.5-4.5 \mathrm{~cm}$, depending on the location of the barb along the length of the rachis. As seen from Table 2, chicken feather barbs have lengths lower than that of the turkey feathers and wool. However, fibers such as cotton with lengths of 2.5-3.5 cm are routinely processed on textile machines and therefore, chicken feather barbs are suitable for processing as natural fibers. The fineness of chicken feather barbs is similar to the average fineness of turkey feather barbs but coarser than that of wool. The strength of chicken feather barbs is similar to that of wool and higher than that of both the plumalaceous and pennaceous barbs of turkey feathers. Elongation of the pennaceous feathers is similar to that of the chicken barbs but the plumalaceous feathers have more than twice the elongation of the pennaceous and chicken feather barbs. All the feather fibers examined have lower elongation than that of wool.

Table 2. Tensile properties of chicken feather barbs compared with turkey feather barbs and wool. Data for turkey feather barbs and wool are from literature $[2,14]$.

\begin{tabular}{lllllll}
\hline Fiber & Fineness, denier & Length, cm & Strength, g/den & Elongation, \% & Modulus, g/den & Moisture regain, \% \\
\hline Chicken barbs & 76 & $1.5-4.5$ & $1.44 \pm 0.46$ & $7.7 \pm 0.85$ & $35.6 \pm 11.15$ & 9.7 \\
Turkey barbs-Pe & 142 & 5.2 & 0.83 & 7.96 & 15.55 & - \\
Turkey barbs-Pl & 55.2 & 4.1 & 0.36 & 16.43 & 4.47 & - \\
Wool & 11 & $4.5-11.5$ & $1.2-1.8$ & $30-40$ & $30-45$ & 16.0 \\
\hline
\end{tabular}

Pe represents pennaceous and Pl represents plumalaceous turkey feather barbs. 1 gram per denier is approximately $130 \mathrm{Mpa}$ 


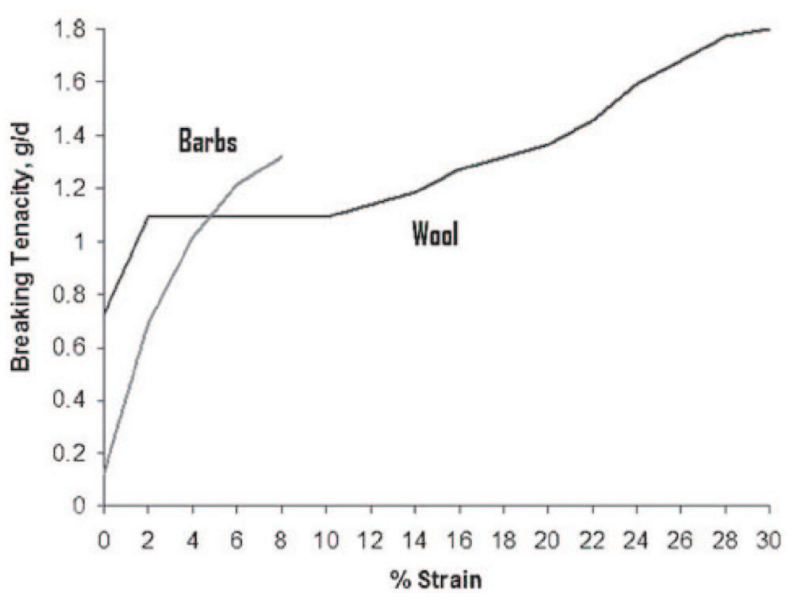

Figure 9. Stress-strain properties of chicken feather barbs compared with that of wool. The stress-strain curves are from the average of 20 fibers.

As seen from Table 2, the chicken feather barbs have modulus similar to that of wool but higher than that of turkey feathers. Modulus indicates the softness and flexibility of a material and the lower the modulus, the softer and flexible the material is. It has been reported that the modulus of feather rachis changes along its length and feathers from different birds have rachis with different modulus [16]. The modulus of chicken feather barbs is similar to that of wool as seen from Table 2 and also to the rachis of goose, swan and ostrich birds with a modulus in the range of 4-8 GPa [16]. However, the surprisingly very low modulus of the plumalaceous turkey feathers indicates that the feathers are very soft and may not be suitable for applications such as composites where toughness is a desirable property. The moisture regain of chicken feather barbs at about $9.7 \%$ is lower than that of wool but higher than that of cellulose fibers such as cotton. Products made from fibers with high moisture regain will be comfortable to wear and relatively easy to process especially during finishing. Although the chicken feather barbs are coarser than wool, the strength, elongation and modulus of the barbs indicates that the fibers have tensile properties similar to that of wool. However, the unique structure of chicken barbs and their low density makes them preferable for many applications. Blending the low density barbs with relatively high density natural fibers and the possible interactions of the barbs with other fibers offers the potential to develop unique properties.

\section{Conclusions}

The structure and properties of chicken feather barbs indicate that barbs are useful as natural protein fibers. The unique structure of the barbs, their low density, large availability and low cost makes barbs preferable fi- bers for several applications such as composites and textiles. The presence of honeycomb structures makes barbs to have low density and also provides air and heat insulating capabilities unlike any other natural fiber. Proteins in chicken feather barbs are of the a-keratin type with about $25 \%$ crystalline protein but the a-keratin in barbs probably has a different structure and arrangement than the proteins in the rachis. Chicken feather barbs have strength of 1.4 grams per denier (180 Mpa) and a modulus of 36 grams per denier (4.7 GPa), similar to that of wool. This study indicates that the structural interaction of the chicken feather barbs with other fibers could provide unique properties to products made using the barbs with other fibers. Further research is necessary to understand the behavior and contribution of chicken feather barbs to the processability and properties of various products.

Acknowledgments - The authors would like to thank Brian Jones with the Center for Materials Research and Analysis in the Physics Department at the University of Nebraska-Lincoln for his help in the X-ray characterization studies. The authors are indebted to the financial support from the University of Nebraska-Lincoln Agricultural Research Division and the support through the Hatch Act.

\section{References}

1. Barone JR, Schmidt WF (2005) Compos Sci Technol 65:173181

2. Jones LN, Riven DE, Tucker DJ (1998) Handbook of Fiber Chemistry, Marcel Dekker, Inc., New York

3. Reddy N, Yang Y (2005) Trends Biotech 23(1):22-27

4. Reddy N, Yang Y (2005) Green Chem 7(4):190-195

5. Reddy N, Yang Y (2005) AATCC Rev 5(7):24-27

6. Reddy N, Yang Y (2005) Polymer 46(15):5494-5500

7. Reddy N, Yang Y (2006) J Agri Food Chem 54:8077-8081

8. Doraiswamy I, Chellamani P (1993) Text Prog 24(1):1-29

9. Ganjyal G, Reddy N, Yang Y, Hanna M (2004) J Appl Polym Sci 93:2627-2633

10. Yang Y, Wang L, Li S (1996) J Appl Polym Sci 59:433-441

11. Huang HC, Hammond EG, Reitmeier CA, Myers DJ (1995) J Am Oil Chem Soc 72(12):1453-1460

12. Boyer RA (1940) Ind Eng Chem 32(12):1549-1551

13. Winandy JE, Muehl JH, Micales JA, Raina A, Schmidt W (2003) In: Proceedings of EcoComp 2003, Queen Mary, University of London, September 1-2, 1-6

14. Evazynajad A, Kar A, Veluswamy S, McBride H, George BR (2002) Mat Res Soc Symp Proc 702:U1.2-U1.4

15. Hernandez-Martinez AL, Santos-Velasco C, Icaza de M, Castano VM (2005) Int J Environ Pollut 23(2):162-178

16. Cameron GJ, Wess TJ, Bonser RHC (2003) J Struct Biol 143:118123

17. Pauling L, Corey RB (1951) Proc Natl Acad Sci USA 37:256258

18. Kraut J (1954) Thesis submitted to California Institute of Technology, 117-151

19. Gibson LJ (2005) J Biomech 38:377-399

20. Butler M, Johnson AS (2004) J Exp Biol 207:285-293

21. Cao J, Billows CA (1999) Polym Int 48:1027-1033

22. Fraser RDB, Macrae TP (1980) Sym Soc Exp Biol 34:211246

23. Venkateshwarlu K, Pillai SP (1960) J Appl Polym Sci 4(11):175-178 